\title{
Catalyzing innovation and knowledge sharing
}

\author{
Librarian 2.0
}

\author{
John Cullen \\ National University of Ireland, Maynooth
}

\begin{abstract}
Generation Y are the first generation to fully put the process of 'prosumption' into practice. Individuals are proactively seeking to generate and share creative outputs as a result of their online activities, and this produces a set of fundamental questions for business librarians, information management specialists and consultants: does our profession adhere to a logic of servicedelivery, which is rapidly becoming obsolete in the context of service-innovation. Suggestions for how information specialists (called librarian 2.0 in this article) can participate in the creation of value for users are offered.
\end{abstract}

Keywords: generation Y, information services, innovation, knowledge sharing, libraries, prosumption

\section{Introduction}

John Cullen lectures in leadership and organizational behaviour in the Department of Business \& Law, National University of Ireland, Maynooth. A librarian by profession he has held library, research and management positions in the private, public and not-for-profit sectors. He won the Library and Information Research Group/Elsevier Research Award in 2001 for his research on library and information management workers in Ireland. He has consultancy and research interests in corporate communication, management learning, organization culture and change. His most recent book, Communication \& Knowledge Sharing at Work: An Introduction, was published by Blackhall Press in 2008 .
Did business leaders, management academics, policy makers or information specialists ever suspect that it would come to this? Alongside the massive global economic restructuring predicted by British Prime Minister Gordon Brown in the first half of 2008, and the credit crunch and soaring fuel prices, the very way in which we conceive of business is undergoing a radical rethink. There has been a tangible acceleration in trying to clarify and understand what to make of social networking trends [1], customer co-creation of value [2] and wikinomics [3], which has not necessarily helped us arrive at a clear answer of what exactly this means for business librarians and information professionals.

The concerns and fears which arose during the first Internet wave in the late 1980s and 1990s that the new paradigm of delivering information electronically would render libraries and traditional library services obsolete were proven unfounded. Our service users may have been internet adaptors, 
ordered their books online and used academic databases, but it quickly became noticeable that the more they tended to engage in these 'new' information activities, the more they also continued to use more 'traditional' services as well. Rather than becoming obsolete, library services became enhanced hybrid services that merged the potential of new technology with traditional services.

Perhaps the reason for this was that the Internet and its possibilities arrived as a new offering to individuals already accustomed to using more traditional library services. We are now seeing the emergence of a generation who know of no world without the Internet; a generation for whom 'on-demand' information services is the norm; a generation who share ideas, concepts and new initiatives openly and freely. This generation will not believe that people rushed home to see new episodes of the X-Files, Seinfeld or the Simpsons in the 1990s, altering their social life to meet the schedules of service providers. Now such schedules are increasingly irrelevant as individuals can pickup and consume their favourite media outputs through a range of technologies.

Accessibility and customizability [4], however, are only part of the new expectations of Generation Y. At this particular stage of late modernity, when urban living and saturated, time-poor lifestyles are increasingly the norm, people seek to make connections in ways that enable them to express themselves and form bonds with others. The term 'prosumer' [5] has recently come into its own as a term that describes the new organizational-consumer relationship that is increasingly preferred, and rapidly becoming expected, by clients and users. There is dwindling contentment with being a passive consumer of products as we are becoming consumers who also actively produce services and offerings.

Eric Von Hippel has been very influential in communicating how competitive advantage in knowledge sectors and industries is accruing to corporate entities who actively share their source code and design products so customers and clients can actively customize them [4]. For example, as I write, my email inbox contains a message from Microsoft with the subject line 'Express Yourself' and offering tips for how to personalize the appearance of my hotmail account. Our understanding of 'Prosumption', however, is rapidly growing beyond the level of customization, and the following examples are perhaps indicative of how this will affect businesses in the future.

\section{The rise of the prosumers}

Since the early 1990s, Trent Reznor of Nine Inch Nails, the American Rock/Industrial band, has been lauded for his highly influential song writing style, production techniques and performances. Whereas other performers of his generation have failed to sustain successful careers, his influence has grown enormously, despite a large number of imitators emerging over the years. This despite the fact that Nine Inch Nails are currently not signed to any major recording label. One of the central reasons why this has happened is that Reznor has transformed his fans from being passive consumers of recordings and concerts into prosumers.

Following a hiatus of almost half a decade, when Reznor battled with personal problems, he returned to a very different music scene which was much more competitive, media-saturated and was endeavouring to accommodate new methods of product delivery (such as iTunes) in the fall-out following Napster's closure in 2001. Increasingly uncomfortable with his relationships with recording companies, Reznor began to freely release the tracks for his songs at Nine Inch Nails remix sites so that fans could create their own versions. The latest Nine Inch Nails album The Slip was released as a free download on the band's website. The site (www.nin.com) also contains a page where fans can access multi-tracks to create their own remixes. Rather than passively awaiting a new release from an artist and then consuming it, prosumers actively engage with the artist in a deeper way and effectively co-create new tracks. They are no longer a fan-base, or a market; they are loyal members of a productive community with similar interests and commitments. Reznor has moved from creating music that was innovative in style and content, to creating art that can, in turn, be innovated' by others. He has allowed his product to become a site of innovation, rather than the result of it.

In Ireland, as in many other countries, the pace of working life, high house prices and levels of personal debt have resulted in many people working longer hours and commuting far greater distances than in the past. Research has demonstrated the toll which this has taken on family life over time, but also on how it has affected civic engagement. On our long commutes, our walkmans and car radios bring us news of people who suffer from human rights abuses, oppression, stigmatization, illness and poverty and we want to do something about this, but we simply do not have the time. 
One of the key things that prosumptive service design offers to individuals is an ability to create some form of value for themselves and for others in a way that is accessible to them. Realizating that the major barrier to individual engagement in human rights issues was the time involved, Amnesty (Ireland) launched an online action centre (www.amnesty.ir/ actioncentre) where individuals can sign up to be part of Amnesty's communication campaigns. Pre-written email templates are available that writers can customize messages on. This represents an example of how an organization has addressed the needs of a difficult to reach target group and used technology to make engagement with human rights activism easier, and has produced immediate results for the organization, which have in turn benefited several others.

It would be myopic to describe these initiatives as technological innovations. I argue that they can be used as examples of two forms of innovation. The first of these is that they are 'management innovations'. Undertaking these approaches involves a fundamental re-think of how the organization's goals match the processes by which it does business. Reznor's goal is to create, disseminate, play and share his music. In choosing to adopt a radically different business model, one which is completely divorced from commercial concerns, Reznor has actually increased his influence and the sustainability of his musical career. Amnesty Ireland have engaged in a process where individuals can engage in their human rights campaigns, but do not have to join the organization, or participate in formal writing groups to do so.

More importantly, though, is the service innovation that these provide. Service innovation was perhaps best described in a recent California Management Review article which is subtitled 'How to Innovate Customers, Not Products' [6]. This article states:

Value is realized, not released, because value is not for exchange but rather in use. The value-creating process is truly the co-creation of value among providers and customers. Offerings in the form of services and products are thus best viewed as 'frozen activities,' or tangible representations of relationships within a value-creating system' [7].

Service innovation is created with a particular value proposition in mind, which enables the user of the service to create value for themselves or their community. The key lesson from this value is created at the point in which the service is used, and although they can facilitate it, it cannot be wholly supplied by the provider. The values created make it easy for users to be prosumers rather than active consumers in allowing creativity and connectivity outside usual scenarios. This connectivity centralizes dialogical communication, rather than making it a uni-directional process.

\section{Information service prosumers}

How often do we think of our client and user communities this way? Librarians have always been in the vanguard of value-adding information services, pushing and promoting new information management tools and services that our users may not immediately see the value of and developing user-centric services and spaces. Library services which do not aspire to move past the user/service paradigm (that is 'we provide a service, you use it as we have designed') are perhaps more noticeable now because of their smaller numbers. Librarians, in short, are well aware of the potential of democratized customization, web 2.0 and social networking tools, but it is extremely difficult to move to a service logic innovation, as so often users of library/information services do not themselves know how they can be proactive users of them. The irony of this should not be underplayed: increasingly there is a wider acceptance of social networking opportunities (just look at the rapid growth and popularity of FaceBook ${ }^{\mathrm{TM}}$ [8], Bebo ${ }^{\mathrm{TM}}$ [9] and MySpace $^{\mathrm{TM}}[10]$ ), but limited understanding of how libraries can be a service innovation environment in their own right.

The ability to create value in information provision is changing from service providers to users, which might indicate that the threat to their positions that librarians began to feel in the late 1980s might now, eventually, become a distinct reality. However true the understanding that all the information you need is at your fingertips actually is, we can be sure that the next generation of CEOs and business leaders actually believe that this is the case. Those of us who are involved in teaching Generation Y, will have noticed a taken-for-granted assumption that everything you need to know is out there, searchable and freely accessible. The value that traditional librarians offered to their service users is gradually, quietly being eroded and we can no longer assume ownership of being custodians, organizers and access-providers to information. When one considers the amount of hype and media 
coverage given to the new paradigm of knowledge sharing and places this in the context of current economic conditions, when the cost cutting dagger is set to drop, managers will look first to services that are considered luxuries, and seek to redeploy the tightening range of organizational resources. Corporate libraries and information services that do not create some form of core value for the organization, may not be top of the queue for downsizing, but they are certainly on the danger list.

\section{Opportunities of the new service logic}

Ironically, the business organizations we work for, and consult to, are suffering from the same anxiety. As we see our traditional industries and markets die as the global map of economic influence and power changes, organizational innovation becomes a crucial factor in how organizations will survive in the future. Innovation, however, is understood differently depending on who you talk to in the organization, and is influenced by multiple factors: their industry; their professional orientation and training; their level of seniority, etc. There are many different understandings of what innovation actually is. Search for articles on innovation and you will come up with articles on service innovation, process innovation, technological innovation, management innovation, etc. This has created much confusion about how organizations should go about making innovation a key component of their culture.

Organizations, by definition, are entities that try to organize, limit and reduce information flows through their structure, and these are internalized by members and groups in cultural understandings of what the organization does and does not do. The by-product of this is that organizations do not share knowledge in the way that maximizes their capabilities to produce or absorb innovation. It has been mentioned previously that corporate librarians are ideally suited to the role of being knowledge-sharing managers in organizations because our roles are not contentious [10], and our profession is usually the only one in the organizational framework that is explicitly concerned with, and trained to share information.

Situated at the intersection between several knowledge flows in the organization, librarians and information consultants are uniquely equipped to unearthing existing, often tacit, knowledge flows in the business that have hitherto not been exploited. A key error in this case would be to try to catch up with what has already been done and customize in a way that focuses exclusively on library services. Who really reads library blogs? Straightforward imitation does not develop any new value for the organization.

Librarian 2.0 does not work or think of their role at the level of the library or information service: they work at the organizational level and challenge assumptions about what the business thinks it knows. They adopt a service logic in order to help every organizational member to find out what they do not know, or better, what they did not know they needed to know. In short they need to create value for everyone in the organization throughout their activities. There is no set template for this type of activity, so the following are some short examples for how this might be done.

It is often said that the definition of a knowledge worker is someone who knows more about their job than their manager does. This creates an unnecessary tension in most work units where middle managers are squeezed between the concerns and workloads of the talent they manage, and the expectations of their senior manager. Knowledge workers are often deeply engaged in the creative projects on which they are working and do not have the time or resources to clearly share what it is they are working on. This is not to say that they do not try to do this. Many of the managers and knowledge workers I have spoken with in the Irish software development sector, for example, have set up wikis in order to make sure that their learning can be shared and their experiences exploited. However, these are often set up with particular subjective understandings of subject material in mind, with the result that the knowledge-sharing effort is not really understood, and ultimately falls flat. If the library or information service took over the establishment and management of these wikis, they could ultimately create a very rich source of value for the organization.

- Managers could more easily understand the activities and outputs of their knowledge workers

- Knowledge workers would not have to re-explain these activities, and the time they would have put into managing and developing corporate wikis will not have been wasted

- Other departments could more easily locate sources of internally available organization information 
- The library service could receive a deep understanding of the work and knowledge flows within the organization, which would in turn help them to better understand and meet the information needs of their internal clients.

It is something of a given that knowledge creation and innovation does not happen in isolation; that it is a social process [1] [4]. The knowledge generation and innovation development capability of an organization is enhanced by greater levels of cultural and social understanding of the organization and its environment. Librarian 2.0 can recombine unused information that already flows through the organization, but is not analysed in any significant way. Many organizations collect data about visitors to their offices, queries received and even about the reasons why employees chose to leave the organization [12] but do not do anything significant with this. Librarians have been trained to deal with user statistics and are equipped to provide solid, robust data to management on the reasons why individuals choose to (or do not choose to) engage with the organization, either as a client or an employee, that cannot be reached through market research or climate surveys.

At the level of strategic information innovation, the information management professionals have a clear advantage over others in terms of their training and their professional orientation. They are adept at dealing with a vast amount of information outputs in all formats and so are ideally placed to sort and analyse external information that arrives with the organization. Analyzing media and policy documents can prove advantageous in gaining a deeper appreciation of what is being said [13], on aggregate, about the organization, and how opinions are being shaped, but when this analysis is taken and compared to internal organizational knowledge, numerous possibilities are presented.

In short, the corporate librarian has the potential to generate an understanding of the organization, its culture and its stakeholders in a way that all CEOs wish they could.

The implications of this for organizational innovation, competitiveness and knowledge sharing are massive. Rather than being another option on the downsizing menu during times of economic uncertainty, librarian 2.0 now has the opportunity to become a critical organizational resource whose influence transcends departmental silos and professional boundaries, and can catalyse management innovation throughout the business.
The practicalities of making this happen remain a concern for library managers who are often working with limited staff and resources, and often with an already high workload. The simple answer is: incrementally. In the past we have been too willing to take on tasks which other parts of the organization were unwilling to engage with, such as sitting on nonvalue adding committees or running intranets (rather than wikis). As we gradually make incremental enhancements, such as those described earlier, we can increase our influence by expanding our role, rather than increasing our workloads.

The mindset shift from being a service-providing information professional to a prosumption-oriented collaborator is significant, and demands that we first understand how the world of our service users, our organizations and their clients is changing. Information science as a discipline is uniquely equipped to develop this understanding in ways that are not native to other fields of study. Information scientists, business information professionals and corporate librarians are perhaps most capable of generating this understanding and rising to meet the challenges that it creates as they are, so to speak, at the 'pointy-end' of the drive for organizations to make innovation part of their culture.

The new logic of service innovation which creates values for users at the point at which they use services requires a way of thinking about preferences for accessing information in the future in which the recipient is actively involved. The core skills of library and information management work will continue to evolve in line with these and will always be needed, but librarian 2.0 will need to engage with new understandings, and expectations of information use will need to develop along side. As Generation Y begins to grow up, its members who choose to join us in business library and information management work will be best placed to help the profession meet these new understandings. In the meantime, we have to make sure that we are ready to meet them.

\section{References}

[1] Cullen, John (2008) 'Professionalizing Knowledge Sharing and Communications: Changing Roles for a Changing Profession', Business Information Review 25(1): 53-7.

[2] Prahalad, C. K. and Ramaswamy, Venkat (2004) 'Co-creating Unique Value with Customers', Strategy \& Leadership 32(4): 4-9. 
[3] Tapscott, Don and Williams, Anthony D. (2007) Wikinomics: How Mass Collaboration Changes Everything. London: Atlantic Books.

[4] Hippel, Eric Von (2005) Democratizing Innovation. Oxford and Cambridge, MA: MIT Press.

[5] Toffler, Alvin (1970) Future Shock. London: Bodley Head.

[6] Michel, Stefan, Brown, Stephen W. and Gallan, Andrew S. (2008) 'Service Logic Innovations: How to Innovate Customers not Services', California Management Review 50(3): 49-65.

[7] Ibid., pp. 50-1.

[8] www.facebook.com

[9] www.bebo.com
[10] www.myspace.com

[11] Ives, William, Torrey, Ben and Gordon, Cindy (2000) 'Knowledge Sharing is a Human Behaviour', in Daryl Morey, Mark Maybury and Bhavani Thuraisingham (eds) Knowledge Management: Classic and Contemporary Works, pp. 99-129. London: The MIT Press.

[12] Findlay, Jacquie (2003) 'Cockroaches of Human Resources Practice?: Exit Interviews and Knowledge Management', Business Information Review 20(3): 127-35.

[13] Cullen, John (2005) 'Corporate Identity and Reputation Intelligence: Emerging Opportunities for Information Professionals', Business Information Review 22(2): 101-6. 